\title{
CARACTERIZAÇÃO PALINOLÓGICA DE ESPÉCIES DE MICROPHOLIS (GRISEB) PIERRE (SAPOTACEAE) PARA A BAHIA
}

\author{
$\underline{\text { Jamile Peixoto }}^{1}$; Cláudia Elena Carneiro $^{2}$; Paulino Pereira Oliveira $^{3}$ \\ 1. Bolsista PIBIC-Af/CNPq, Graduando em Ciências Biológicas, Universidade Estadual de Feira de Santana, e-mail: \\ jamilipeixoto08@hotmail.com \\ 2. Orientador, Departamento de Ciências Biológicas, Universidade Estadual de Feira de Santana, e-mail: \\ cecarneiro@gmail.com \\ 3. Co-orientador, Departamento de Ciências Biológicas, Universidade Estadual de Feira de Santana, e-mail: \\ paulino.pereira@gmail.com
}

PALAVRAS-CHAVE: Pólen, taxonomia, morfologia.

\section{INTRODUÇÃO}

Sapotaceae é uma família botânica pertencente à ordem Ericales (APG IV), com aproximadamente 1.309 espécies distribuídas ao longo da região neotropical (Faria, et $a l, 2017)$. As principais características desta família são a presença de látex, folhas em disposição alternas ou raramente opostas, geralmente sem estípulas, e o hábito arbóreo ou arbustivo. Sapotaceae possui importância econômica com látex e madeira, utilizados para produção de borracha e móveis (Pennington, 1990). No Brasil, é representada por 12 gêneros e 234 espécies (Flora 2020). Dentre estes 12 gêneros, Micropholis destacase por ser o terceiro maior da família e possuir distribuição exclusivamente neotropical, ocorrendo no Centro e Sul da América e Índias Ocidentais. Micropholis caracteriza-se principalmente por ser árvores ou arbustos com folhas de nervuras finamente estriadas e estritamente paralelas umas às outras, havendo pouca diferenciação entre a nervura de segunda e terceira ordem (Pennington, 1990). Economicamente fornece produtos, assim como a família, com ênfase para espécie M. venulosa comumente conhecida como curupixá, por ser muito utilizada na indústria madeireira (Cruz \& Carvalho, 2003). No Brasil, o gênero é representado por 29 espécies, sendo referidas para a Bahia sete espécies (Carneiro, et al, 2015). Das espécies referidas para a Bahia, quatro encontramse na Lista Vermelha da Flora do Brasil, com destaque para M. emarginata considerada endêmica da Bahia e listada como "em perigo de extinção" (EN., CNCFlora 2018). Até o momento inexistem trabalhos palinológicos para as espécies deste gênero na Bahia, elevando a importância em reunir maiores características destes táxons. Sabendo-se da importância econômica do gênero e pela baixa disponibilidade de dados na literatura, este trabalho objetivou caracterizar a morfologia polínica das espécies de Micropholis que ocorrem na Bahia, a fim de contribuir para taxonomia e um melhor conhecimento do grupo, além de ampliar a coleção da Palinoteca do Estado.

\section{MATERIAL E MÉTODOS}

Inicialmente foi realizado um levantamento acerca da distribuição das espécies de Micropholis na Bahia, através de sites como Species Link e Reflora, para em seguida serem obtidos botões florais das duplicatas disponíveis nos seguintes herbários: HUEFS (Herbário da Universidade Estadual de Feira de Santana) e CEPEC (Herbário Centro de 
Pesquisas do Cacau). As anteras, retiradas dos botões florais, foram submetidas à acetólise (Erdtman, 1960), sendo o sedimento polínico resultante, montado em lâminas, com gelatina glicerinada, para as análises em microscópio de luz. Os grãos de pólen foram fotomicrografados para ilustrar as espécies estudadas.

A descrição da morfologia polínica seguiu a terminologia de Punt et al. (2007).

\section{RESULTADOS E DISCUSSÃO}

Das sete espécies citadas para Bahia, apenas quatro foram analisadas no presente estudo: Micropholis crassipedicellata (Mart. \& Eichler) Pierre, M. emarginata T.D. Penn., M. gardneriana (A. DC.) Pierre e M. guyanensis (A. DC.) Pierre (Figura 1). As espécies não estudadas decorreram da indisponibilidade de material botânico fértil, ou seja, sem grãos de pólen.

As espécies estudadas compartilharam caracteres morfopolínicos como a abertura do tipo cólporo, (variando entre 3 e 4 aberturas), âmbito triangular em vista polar, e a unidade de dispersão em mônade. Os caracteres polínicos que diferiram nas espécies foram o tamanho e a forma. Em relação ao tamanho, as espécies analisadas apresentaram grãos de pólen com tamanho médio, à exceção de $M$. emarginata com grãos de pólen pequenos e $M$. guyanensis com grãos de pólen pequeno a médios. Quanto à forma, grãos de pólen prolatos foram verificados em M. gardneriana, $M$. emarginata e $M$. guyanensis; a forma subprolata foi encontrada em $M$. crassipedicellata.

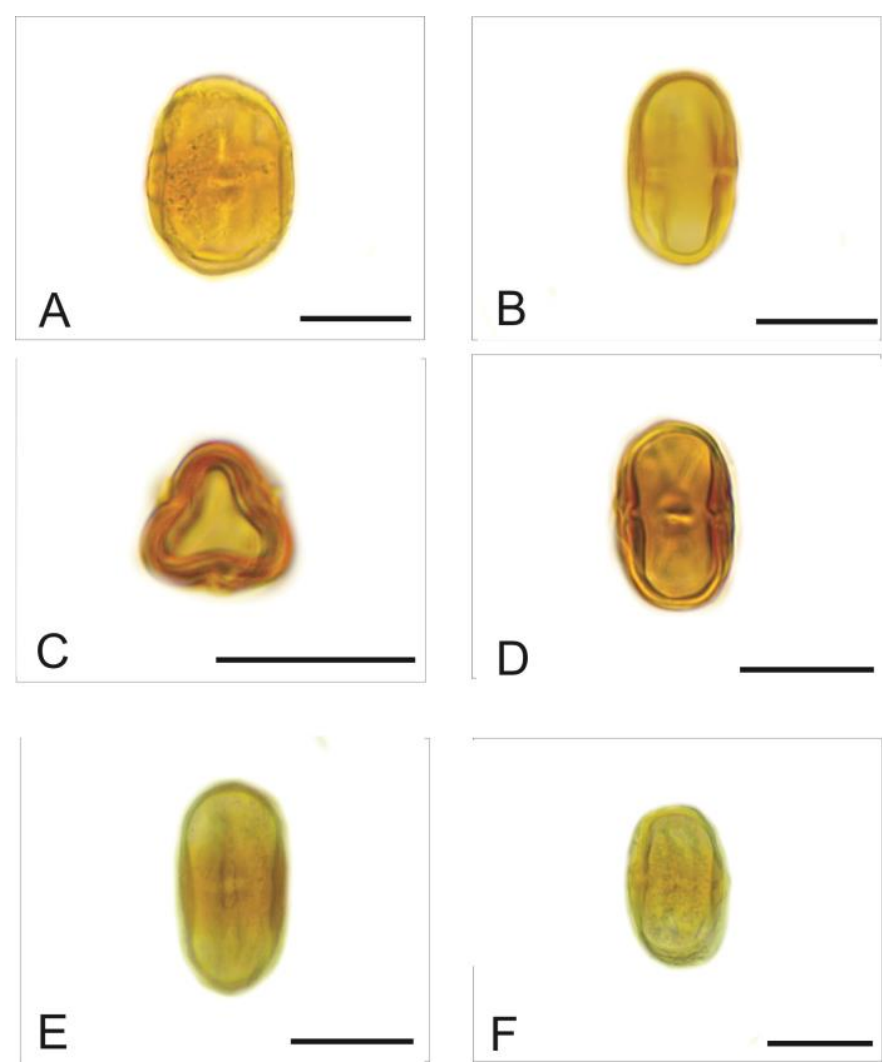

Figura 1. Morfologia dos grãos de pólen de Micropholis. A- M. crassipedicellata (Mart. \& Eichler) Pierre, vista equatorial; B- M. guyanensis (A. DC.) Pierre, vista equatorial; C-D- M. emarginata T.D. Penn., C. vista equatorial; D. vista polar e E-F- M. gardneriana (A.DC.) Pierre, vista equatorial. Barra = $10 \mu \mathrm{m}$. 
As descrições realizadas corroboram com as informações de Pennington, (1990) e Harley (1991). Contudo, o trabalho de Melo et al, (2017) descreve características da morfologia polínica de $M$. cuneata Pierre ex Glaziou, um sinônimo heterotípico de $M$. crassipedicellata (Mart. \& Eichler) Pierre. Os resultados encontrados por esses autores diferem dos registrados no presente estudo em relação ao número apertural e a forma dos grãos de pólen. Em M. cuneata os grãos de pólen foram descritos com forma prolata e presença de 4-(3)- aberturas, já em $M$. crassipedicellata a forma observada foi subprolata, com apenas 3 aberturas. Essas foram as principais diferenças encontradas dentre as espécies analisadas, demonstrando assim a importância de mais estudos em morfologia polínica, para uma melhor caracterização do grupo o que poderá auxiliar na taxonomia do mesmo.

\section{CONSIDERAÇÕES FINAIS}

O presente estudo revelou que, caracteres como o número de aberturas e a forma dos grãos de pólen, diferiram nas espécies analisadas. Sendo assim, tais caracteres podem contribuir com fins taxonômicos para o gênero Micropholis e outras aplicações que envolvem a palinologia. No entanto, considerando o conjunto amostral limitado, que foi utilizado no presente estudo, reconhecemos a necessidade de ampliar o número de espécimes estudadas par um melhor diagnóstico da morfologia polínica. Contudo, esse estudo é o primeiro a levantar dados palinológicos para o gênero no Estado da Bahia.

\section{REFERÊNCIAS}

APG IV. 2016. An update of the Angiosperm Phylogeny Group classification for the orders and families of flowering plants. APG IV. Botanical Journal of the Linnean Society 2016: 1-20.

CARNEIRO, C.E.; ALVES-ARAUJO, A.; ALMEIDA Jr., E.B. 2013. Sapotaceae in Lista de Espécies da Flora do Brasil. Jardim Botânico do Rio de Janeiro. (http://floradobrasil.jbrj.gov.br/jabot/floradobrasil/FB217). Acesso em, 13/08/2018.

CNCFlora. 2018. Centro Nacional de Conservação da Flora. Disponível em $<$ http://cncflora.jbrj.gov.br/portal/pt-br/listavermelha/SAPOTACEAE $>$. Acesso em 29 julho 2018.

CRUZ, E.D. \& CARVALHO, J.E.U. 2003. Biometria de frutos e sementes e germinação de curupixá (Micropholis $c f$. venulosa Mart. \& Eichler -Sapotaceae). Acta Amazonica 33(3): 389-398.

ERDTMAN, G. 1960. The acetolysis method. A revised description. Svensk Botanisk Tidskrift, Stockolm, 39: 561-564.

HARLEY, M.M. 1991. The pollen morphology of the Sapotaceae. Kew Bulletin, vol. 46. No 3.

MELO, M.R.F; Corrêa, A.M.S \& Cruz-Barros, M.A.V., 2017. Flora Polínica da Reserva do Parque Estadual das Fontes do Ipiranga (São Paulo, Brasil), Hoehnea 44(1): 96-102. 
PENNINGTON, T.D. Flora Neotropica - Monograph 52: Sapotaceae. New York: New York Botanical Garden, 1990.

PUNT, W.; BLACKMORE, S.; HOEN, P.P. \& LE THOMAS, A., 2006. Glossary of pollen and spore terminology, Review of Palaeobotany and Palynology 143, 1-81 